\author{
dspace.vutbr.cz
}

\title{
Heat treatment induced phase transformations in zirconia and yttriastabilized zirconia monolithic aerogels
}

TORRES RODRÍGUEZ, J.; KALMÁR, J.; MENELAOU, M.; ČELKO, L.; DVOŘÁK, K.; CIHLÁŘ, J.; CIHLÁŘ, J.; KAISER, J.; GYŐRI, E.; VERES, P.; FÁBIÁN, l.; LÁZÁR, I.

Journal Of Supercritical Fluids

2019, vol. 149, July 2019, pp. 54-63

ISSN: 0043-1648

DOI: https://doi.org/10.1016/j.supflu.2019.02.011

Accepted manuscript

(C) 2019. This manuscript version is made available under the CC-BY-NC-ND 4.0 license

(http://creativecommons.org/licenses/by-nc-nd/4.0/), doi:

https://doi.org/10.1016/j.supflu.2019.02.011

Final version available from

https://www.sciencedirect.com/science/article/pii/S089684461830771X 


\section{Accepted Manuscript}

Title: Heat Treatment Induced Phase Transformations in Zirconia and Yttria-Stabilized Zirconia Monolithic Aerogels

Authors: Jorge Torres-Rodríguez, József Kalmár, Melita Menelaou, Ladislav Čelko, Karel Dvořak, Jaroslav Cihláŕ, Jaroslav Cihlař Jr, Jozef Kaiser, Enikő Győri, Péter Veres,

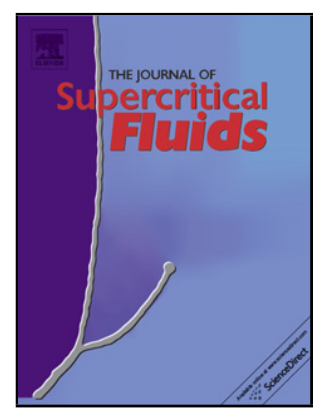
István Fábián, István Lázár

PII:

DOI:

Reference:

S0896-8446(18)30771-X https://doi.org/10.1016/j.supflu.2019.02.011

To appear in: SUPFLU 4471

Received date: $\quad 14$ November 2018

Revised date: $\quad 31$ January 2019

Accepted date: $\quad 11$ February 2019

Please cite this article as: Torres-Rodríguez J, Kalmár J, Menelaou M, Čelko L, Dvořak K, Cihlár J, Cihlař J, Kaiser J, Győri E, Veres P, Fábián I, Lázár I, Heat Treatment Induced Phase Transformations in Zirconia and YttriaStabilized Zirconia Monolithic Aerogels, The Journal of Supercritical Fluids (2019), https://doi.org/10.1016/j.supflu.2019.02.011

This is a PDF file of an unedited manuscript that has been accepted for publication. As a service to our customers we are providing this early version of the manuscript. The manuscript will undergo copyediting, typesetting, and review of the resulting proof before it is published in its final form. Please note that during the production process errors may be discovered which could affect the content, and all legal disclaimers that apply to the journal pertain. 


\section{Heat Treatment Induced Phase Transformations in Zirconia and Yttria- Stabilized Zirconia Monolithic Aerogels}

Jorge Torres-Rodríguez, , József Kalmár ${ }^{b, c, *}$, Melita Menelaou $^{a}$, Ladislav Čelko ${ }^{a, *}$,

Karel Dvořak ${ }^{d}$, Jaroslav Cihlár̆a , Jaroslav Jr Cihlařa , Jozef Kaiser ${ }^{a}$, Enikö Györi ${ }^{b}$,

Péter Veres ${ }^{b}$, István Fábián ${ }^{b, c}$, István Lázár ${ }^{b}$

${ }^{a}$ Central European Institute of Technology, Brno University of Technology, Purkyňova 123, 61200 Brno, Czech Republic

${ }^{\mathrm{b}}$ Department of Inorganic and Analytical Chemistry, University of Debrecen, Egyetem tér 1, Debrecen, H-4032 Hungary

${ }^{c}$ MTA-DE Redox and Homogeneous Catalytic Reaction Mechanisms Research Group, Egyetem tér 1, Debrecen, H-4032 Hungary

d AdMaS Center, Faculty of Civil Engineering, Brno University of Technology, Purkyňova 139, 61200 Brno, Czech Republic

*Corresponding authors: J. Kalmár: kalmar.jozsef@ science.unideb.hu

L. Čelko: celko@fme.vutbr.cz 


\title{
Graphical abstract
}

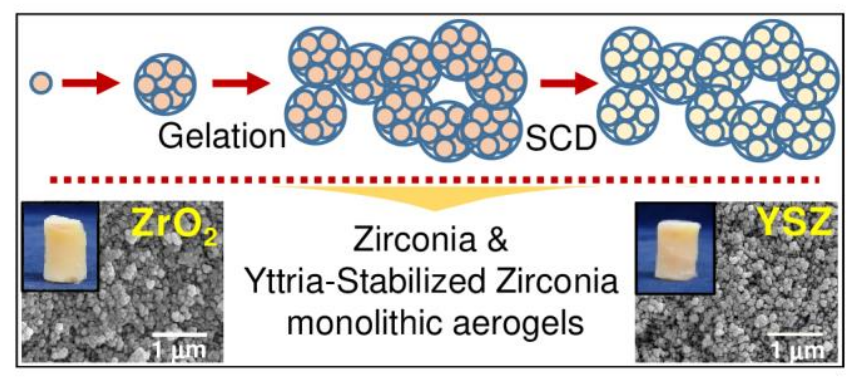

\section{Highlights}

- $\mathrm{ZrO}_{2}$ and $\mathrm{YSZ}$ aerogels derived by combining sol-gel method and supercritical drying

- Evolution of crystallinity was observed by in-situ XRD measurements up to $1200{ }^{\circ} \mathrm{C}$

- Phase transformation of zirconia $\left(\mathrm{ZrO}_{2}\right)$ is affected by crystallite size growth

- Yttria-stabilized zirconia (YSZ) aerogel forms stable single-phase $t-\mathrm{ZrO}_{2}$ at $455{ }^{\circ} \mathrm{C}$

\begin{abstract}
Monolithic, structurally stable zirconia $\left(\mathrm{ZrO}_{2}\right)$ aerogels can be used in high temperature applications and as medical implants. The macroscopic properties of these solids can be fine-tuned by the appropriate thermal treatment of the amorphous aerogels. Herein, we investigate the thermally induced phase transitions of $\mathrm{ZrO}_{2}$ and yttriastabilized zirconia (YSZ) monolithic aerogels. All aerogels were produced by an acidcatalyzed sol-gel technique and subsequent supercritical drying (SCD). A complete reaction mechanism is proposed for the formation of the wet gel network. Also, the phase transformations taking place during calcination were followed as a function of the temperature by in-situ X-ray diffraction measurements. Composition and size of the forming crystallites were calculated from the XRD data. Phase transition is controlled by the temperature-dependent growth of crystallite size during calcination up to $1200{ }^{\circ} \mathrm{C}$. Both tetragonal and monoclinic zirconia form in pure $\mathrm{ZrO}_{2}$ aerogels, and a single tetragonal phase forms in YSZ aerogels.
\end{abstract}


Keywords: aerogel; zirconia; yttria-stabilized zirconia; heat treatment; phase transformation.

\section{Introduction}

Aerogels are highly porous materials, which are composed of interconnected nanoparticles in an open mesoporous 3D structure. [1] Generally, the formation of aerogels involves the formation of a colloidal suspension (sol), that is followed by the transition of the sol into a gel, and finally, the extraction of the solvent while keeping the solid backbone intact. [2, 3] They are excellent candidates for thermal and acoustic insulation, radiation detectors, drug delivery systems and catalyst supports. [4-6]

Zirconia $\left(\mathrm{ZrO}_{2}\right)$ is a high-temperature oxide which has excellent heat resistance, high toughness, abrasion resistance and chemical resistance. It has been studied for several applications in catalysis, in engineering as a structural material and as a semiconductor. $[7,8]$ In order to improve the performance of $\mathrm{ZrO}_{2}$-based materials, a high surface area and the phase stability of zirconia are desirable characteristics. Pure $\mathrm{ZrO}_{2}$ is a polymorphic oxide that has three well-known thermodynamically stable crystalline phases: $i)$ the monoclinic phase $\left(m-\mathrm{ZrO}_{2}\right)$ which is stable from room temperature to 1170 ${ }^{\circ} \mathrm{C}$, ii) the tetragonal phase $\left(t-\mathrm{ZrO}_{2}\right)$ which is stable between 1170 and $2370{ }^{\circ} \mathrm{C}$ and $\left.\mathrm{iii}\right)$ the cubic $\left(c-\mathrm{ZrO}_{2}\right)$ phase exists between 2370 and $2680{ }^{\circ} \mathrm{C}$. A metastable tetragonal zirconia is also known and can be stable below $650{ }^{\circ} \mathrm{C}$. [9] The crystalline phase of zirconia affects its macroscopic structural and textural properties, such as the specific surface area, porosity, density and particle size. When zirconia is stabilized in the tetragonal phase, high strength, toughness and wear resistance rise. Several studies have indicated that pure $t-\mathrm{ZrO}_{2}$ can be stabilized in the nanoscale at temperatures lower than 
$1170{ }^{\circ} \mathrm{C}$ under well-adjusted synthetic conditions. [10-12] The calcination temperature (from 400 to $700{ }^{\circ} \mathrm{C}$ ) has a direct effect on the transformation of zirconia from $t-\mathrm{ZrO}_{2}$ to $m-\mathrm{ZrO}_{2}$, and that this transformation is accompanied by the growth of the crystallite size. In addition to the structural stability of zirconia, the textural properties, such as the surface area, are also affected by the synthetic methods. [13-17] In spite of the numerous efforts to produce zirconia aerogel monoliths, the resulting ceramics have poor thermal stability that renders them less attractive in high temperature applications.

Several chemical approaches are focused on the stabilization of $t-\mathrm{ZrO}_{2}$. One approach is the doping of zirconia by di- or trivalent cations $\left(\mathrm{M}^{3+}, \mathrm{M}^{2+}\right)$ with suitable ionic radii in order to replace the $\mathrm{Zr}^{4+}$ in the sublattice. The charge in these hybrids is balanced by the formation of oxygen vacancies. A representative example is the case of $\mathrm{Y}^{3+}$ ions, the use of which results in the stabilization of high-temperature zirconia phases at room temperature. Typically, 6-8 mol \% of $\mathrm{ZrO}_{2}$ is substituted by $\mathrm{Y}_{2} \mathrm{O}_{3}$, and the resulting hybrid is called yttria-stabilized zirconia (YSZ). [18-20] Also, several attempts have been reported to enhance the crystallinity, as well as the mechanical properties of zirconia aerogels by hybridization with silica. [21-23] It is important to understand the role of critical variables affecting the stability of $t-\mathrm{ZrO}_{2}$ in monolithic aerogels in order to fine tune the macroscopic characteristics. $[10,19,24]$

In spite of the large variety of the above mentioned approaches, much less work has been devoted to investigate the intimate effect of heat treatment on amorphous $\mathrm{ZrO}_{2}$ and YSZ aerogels. In this paper we report the synthesis of monolithic $\mathrm{ZrO}_{2}$ and $\mathrm{YSZ}$ aerogels through a facile acid-catalyzed sol-gel method. We thoroughly investigate the effect of heat treatment on the crystallographic evolution and the phase stability of both systems starting from the as-prepared amorphous aerogels.

\section{Experimental}




\subsection{Materials}

All chemicals were purchased from Sigma-Aldrich and used as received. Zirconium(IV) propoxide $\left(\mathrm{Zr}\left(\mathrm{OC}_{3} \mathrm{H}_{7}\right)_{4}, 70 \mathrm{wt} \%\right.$ in $n$-propanol), yttrium(III) nitrate hexahydrate $\left(\mathrm{Y}\left(\mathrm{NO}_{3}\right)_{3} \cdot 6 \mathrm{H}_{2} \mathrm{O}\right)$, nitric acid $\left(\mathrm{HNO}_{3}, 70 \%\right)$, acetone and $n$-propanol (anhydrous) were used for the synthesis.

\subsection{Synthesis of wet gels}

$\mathrm{ZrO}_{2}$ wet gels were prepared in the following 4 steps: i) a $1 \mathrm{M} \mathrm{HNO}_{3}$ solution was prepared in n-propanol (catalyst solution); ii) in a separate beaker, $2.5 \mathrm{~mL}$ zirconium(IV) propoxide was mixed with $12.5 \mathrm{~mL}$-propanol and with $0.75 \mathrm{~mL}$ catalyst solution under continuous stirring (solution A); iii) a third solution was prepared from $0.75 \mathrm{~mL}$ distilled water and $12.5 \mathrm{~mL} n$-propanol (solution B) and $i v$ ) solution B was slowly added to solution A and stirred vigorously with a magnetic stir bar for 5 minutes. [25] After these steps, the mixture was poured into cylindrical plastic molds, hermetically sealed and let to stand at room temperature for one day in order to form the wet $\mathrm{ZrO}_{2}$ gel. The final molar ratio of $\mathrm{Zr}\left(\mathrm{OC}_{3} \mathrm{H}_{7}\right)_{4}, \mathrm{HNO}_{3}$ and $\mathrm{H}_{2} \mathrm{O}$ were 1:2:3.

For the preparation of YSZ wet gels, yttrium(III) nitrate was initially dissolved in the mixture of $n$-propanol and $\mathrm{HNO}_{3}$ (solution B), before zirconium(IV) propoxide (solution A) was slowly added into it. In the case of the YSZ gels, the final molar ratio of $\mathrm{Zr}\left(\mathrm{OC}_{3} \mathrm{H}_{7}\right)_{4}, \mathrm{HNO}_{3}, \mathrm{H}_{2} \mathrm{O}$, and $\mathrm{Y}\left(\mathrm{NO}_{3}\right)_{3}$ were 1:2:3:0.14. Thus, the YSZ aerogel nominally contains $7 \mathrm{~mol} \%$ yttrium.

The wet gels were transferred to perforated aluminum holders and aged during $24 \mathrm{~h}$ at room temperature in $n$-propanol. After this procedure, the wet gels were soaked in acetone which was replaced for fresh solvent in every $24 \mathrm{~h}$ for 6 days to ensure that all liquids in the gel networks are fully replaced by acetone. Our experience is that extensive and slow 
solvent exchange is necessary to ensure the batch-by-batch reproducibility of both the microscopic and the macroscopic structures of the final aerogels. This aging period is also necessary for secondary chemical processes to reach equilibrium before supercritical drying.

\subsection{Supercritical drying (SCD)}

The aged wet gels were dried in an autoclave with supercritical $\mathrm{CO}_{2}$ by using the technique of medium temperature supercritical drying. The process is detailed in a previous publication. [26] In a typical drying procedure, the autoclave was pressurized with liquid $\mathrm{CO}_{2}$ to $5.8 \mathrm{MPa}$, and subsequently, the temperature was raised to $80^{\circ} \mathrm{C}$, while the pressure was controlled at $18 \mathrm{MPa}$. After keeping this supercritical state for $3 \mathrm{~h}$, the system was slowly depressurized to atmospheric pressure at the rate of $2 \mathrm{bar} / \mathrm{min}$. When the autoclave was cooled down to room temperature, as-prepared monolithic $\mathrm{ZrO}_{2}$ and YSZ aerogels were obtained.

A critical requirement for successful supercritical drying is to ensure that the asprepared monoliths are completely free of acetone. Thus, the acetone content of $\mathrm{CO}_{2}$ is monitored during the initial steps of the process before setting the supercritical conditions. [26] Furthermore, the IR spectra of the as-obtained aerogels should be free of $-\mathrm{C}=\mathrm{O}$ resonance peaks arising from adsorbed acetone.

\subsection{Heat treatment}

All procedures were carried out in a standard chamber under atmospheric conditions. First, the as-prepared aerogels were kept at $300{ }^{\circ} \mathrm{C}$ for $3 \mathrm{~h}$ in order to remove the residual water and solvents. Subsequently, the aerogels were calcined at temperatures between $500{ }^{\circ} \mathrm{C}$ and $1200{ }^{\circ} \mathrm{C}$ for $2 \mathrm{~h}$. The target temperature was reached with a heating rate of 
$10.0{ }^{\circ} \mathrm{C} \mathrm{min}-1$. The as-obtained aerogels are denoted as follows. $\mathrm{ZrO}_{2}-\mathrm{AO}$ and YSZ-AO: drying at $300{ }^{\circ} \mathrm{C} ; \mathrm{ZrO}_{2}-500$ and $\mathrm{YSZ}-500$ : calcination at $500{ }^{\circ} \mathrm{C} ; \mathrm{ZrO}_{2}-1200$ and YSZ1200: calcination at $1200^{\circ} \mathrm{C}$.

\subsection{Characterization techniques}

Thermogravimetric analysis (TGA), differential scanning calorimetry (DSC) and coupled mass spectrometry (MS) were carried out simultaneously in a Netzsch STA 409c/CD apparatus. Analyses were performed with the as-obtained aerogels $\mathrm{ZrO}_{2}-\mathrm{AO}$ and YSZ-AO in synthetic air atmosphere (14 vol. \% of $\mathrm{O}_{2}$ in $\mathrm{Ar}$ ) using $\mathrm{Al}_{2} \mathrm{O}_{3}$ crucibles with a heating rate of $10{ }^{\circ} \mathrm{C} \min ^{-1}$ from $20{ }^{\circ} \mathrm{C}$ to $1300{ }^{\circ} \mathrm{C}$. The MS signal of $m / z: \mathrm{H}_{2} \mathrm{O}$ : 18, $\mathrm{CO}: 28, \mathrm{CO}_{2}: 44, \mathrm{NO}_{\mathrm{x}}: 14,30$ and 46 were recorded.

The phase recognition of the as-obtained aerogels was performed both by in-situ and ex-situ X-ray diffraction (XRD) measurements during the various stages of heat treatment. The X-Ray powder diffractometer (Empyrean; Panalytical) was set up in the Bragg-Brentano parafocusing $\theta-\theta$ reflecting geometry with $\mathrm{Cu} K \alpha$ radiation $(\lambda=0.154$ $\mathrm{nm}$ ), Ni filter, fix divergence slits, and a 1-D position sensitive detector operated at the current of $45 \mathrm{~mA}$ and voltage of $40 \mathrm{kV}$. The diffraction pattern was collected from $22^{\circ}$ to $37^{\circ}$ with the step size of $0.0263^{\circ}$ at the rate of $96 \mathrm{~s}$ per step. Total scan time was 5 min. The measurements were performed in duplicate. Data were processed using the HighScore+ software and ICDD PDF 2 and ICSD 2012 databases. Quantitative phase analysis was realized according to the Rietveld method using the fundamental parameters approach. Crystallite size $(D)$ was determined from the X-ray line broadening using Scherrer's equation;

$$
D=\mathrm{K} \lambda / \beta \cos \theta
$$


(where $\mathrm{K}$ is the shape factor $(0.89), \lambda$ is the $\mathrm{X}$-ray wavelength $(0.154 \mathrm{~nm}), \beta$ is the line broadening at half of the maximum intensity in radians (full width at half maximum: FWHM), and $\theta$ is the Bragg angle). [27] The FWHM values were determined by fitting the XRD pattern peaks for the lattice planes (111) and (011) for monoclinic and tetragonal, respectively. Additionally, to the determined FWHM, Warren's correction was applied;

$$
\beta=\sqrt{\left(B^{2}-\mathrm{b}^{2}\right)}
$$

(where $\beta$ is the FWHM after correction, $B$ is the calculated FWHM and b is the FWHM of the fully crystalline $\mathrm{LaB}_{6}$ standard). When required, Rietveld refinement was performed by means of fitting the X-ray diffraction patterns using the commercially available peak fitting software HighScore+.

Nitrogen gas adsorption-desorption measurements were performed in a Quantachrome 2200e porosimeter at $77.35 \mathrm{~K}$. The aerogels were degassed at $100{ }^{\circ} \mathrm{C}$ for $14 \mathrm{~h}$ before each measurement. The degassing temperature was chosen to be $100^{\circ} \mathrm{C}$ in order to avoid any structural changes in $\mathrm{ZrO}_{2}-\mathrm{AO}$ and YSZ-AO samples. Data were recorded and analyzed by the NovaWin 11.0 software. Surface area was calculated using the Brunauer-EmmettTeller (BET) method from the adsorption part of the isotherm. The descriptions of the BET and $t$-plot methods, together with the definition of the $C$-constant are given in prior literature and in IUPAC technical notes. [28, 29] Pore size distribution was calculated according to the Barrett-Joyner-Halenda $(\mathrm{BJH})$ model from the desorption branch of the isotherm.

Scanning electron micrographs (SEM) were recorded by a Hitachi S-4300 instrument equipped with a Bruker energy dispersive X-ray spectroscope. Fresh fracture surfaces were covered by a sputtered gold conductive layer. Typically, a $5-15 \mathrm{kV}$ accelerating voltage was used for taking high-resolution pictures. 


\section{Results and discussion}

The as-obtained aerogels are denoted as follows. $\mathrm{ZrO}_{2}-\mathrm{AO}$ and $\mathrm{YSZ}-\mathrm{AO}$ were dried at $300{ }^{\circ} \mathrm{C}$ but not calcined; $\mathrm{ZrO}_{2}-500$ and $\mathrm{YSZ}-500$ were calcined at $500{ }^{\circ} \mathrm{C} ; \mathrm{ZrO}_{2}-1200$ and YSZ-1200 were calcined at $1200{ }^{\circ} \mathrm{C}$. The details of aerogel preparation are given in the Experimental section.

\subsection{Mechanism of formation of $\mathrm{ZrO}_{2}$ and $\mathrm{YSZ}$ wet gels}

Both the $\mathrm{ZrO}_{2}$ and YSZ aerogels were synthesized by hydrolyzing the appropriate precursors using an acidic catalyst $\left(\mathrm{HNO}_{3}\right)$. The proposed molecular mechanisms of the hydrolytic and polycondensation reactions leading to the formation of 3D gel networks are shown in Schemes 1 and 2. For the sake of visibility, the structures of octacoordinated zirconium ions are shown in a simplified form, indicating the presence of unhydrolyzed alkoxide groups, as well as bridging oxo- and/or terminal hydroxo groups.

Under acidic conditions, the first step is the protonation of an alkoxide group as shown in Scheme 1. The assumption that alkoxide group is protonated first, even in the presence of hydroxyl groups is supported by the two orders of magnitude higher protonation constant of propoxide $(\log K=16.1)$ than that of hydroxide $(\log K=14.0)$. [30] Upon protonation, the partial positive charge on zirconium ion is increased, leading to a nucleophilic attack by the partially negatively charged oxygen atom of a water molecule. In a push-pull mechanism, the better leaving group $\mathrm{ROH}$ alcohol is split off, leaving the extra positive charge behind. Since the positive charge is located on the protonated hydroxyl group (which is the less basic group) and is repulsed by the positive charge of the zirconium ion, it is transferred to the surrounding water. Once all alkoxide groups are hydrolyzed, a completely hydrolyzed intermediate is formed (denoted as $\mathrm{Hydr}-\mathrm{Zr}$ in Scheme 1). Although hydroxyl groups are somewhat weaker bases than alkoxide groups, 
they can be protonated in the Hydr- $\mathrm{Zr}$ complexes at high $\left[\mathrm{H}^{+}\right]$concentration, resulting in an accumulation of the protonated species Prot-Zr (Scheme 1). This may be an inactive intermediate in the forthcoming condensation reactions.

A summary of the effect of acid concentration on gel formation is shown in Table S1, Figure S1 and Movie S1 in the Supporting Information, respectively. The rate of hydrolysis is proportional to the acid concentration in the reaction medium, and also the acid concentration has a strong impact on the rate and equilibrium state of the polycondensation reactions (Scheme 2a). Under moderately acidic conditions (@ Moderate $\left[\mathrm{H}^{+}\right]$) both water and alcohol condensation occurs simultaneously. In both cases, the nucleophilic agent is the hydroxyl group of the hydrolyzed complex Hydr-Zr, and the attack leads to the split-off of a water or alcohol molecule and the formation of bridging $\mathrm{Zr}-\mathrm{O}-\mathrm{Zr}$ bonds in the zirconia skeleton. When the acid concentration is increased (@Medium $\left[\mathrm{H}^{+}\right]$), the protonated particles Prot- $\mathrm{Zr}$ are also getting involved in the water condensation process. However, under strongly acidic conditions $\left(@ \mathrm{High}\left[\mathrm{H}^{+}\right]\right)$when most of the zirconia particles are in the protonated form, the reaction slows down very significantly (even near to stop) due to the low concentration of active Hydr-Zr species. That is why the gelation time curves show a minimum with the increasing acid concentration. The polycondensation process binds $\mathrm{Zr}$ atoms into a $3 \mathrm{D} \mathrm{ZrO}_{2}$ network, which forms tiny nanoparticles (primary globules) in the solution. In the primary globules, zirconium atoms mainly relate to each other through oxygen bridges, but other ligands like terminal or bridging $\mathrm{OH}$-groups, as well as coordinated solvent and water molecules are also present. The primary globules bind to each other forming larger nanoparticles called secondary globules, which are the main building blocks of both the wet gel skeleton and later the aerogel skeleton (Scheme 2b). Gelation (the formation of a self-supported wet gel) occurs when the number of secondary globules become so high 
that they get in contact with each other, forming an interconnected solid network. In that process, further condensation reactions occur that connect the globules with covalent chemical bonds.

When all hydrolysis and polycondensation reactions are finished, the wet $\mathrm{ZrO}_{2}$ gel is dried under supercritical condition with carbon dioxide. After supercritical drying, the asobtained aerogels may contain traces of unhydrolyzed alkoxy groups, as well as solvent molecules and hydrating water. Nitric acid may be present as a counter ion in the protonated structure. The residual organic moieties may serve as the carbon source in the high-temperature heating processes.

Scheme 1. The molecular mechanism of the acid-catalyzed hydrolysis of the $\operatorname{Zr}(\mathrm{IV})$ precursor leading to the formation of $\mathrm{ZrO}_{2}$ and $\mathrm{YSZ}$ wet gels.

\section{Acid-catalyzed hydrolysis}
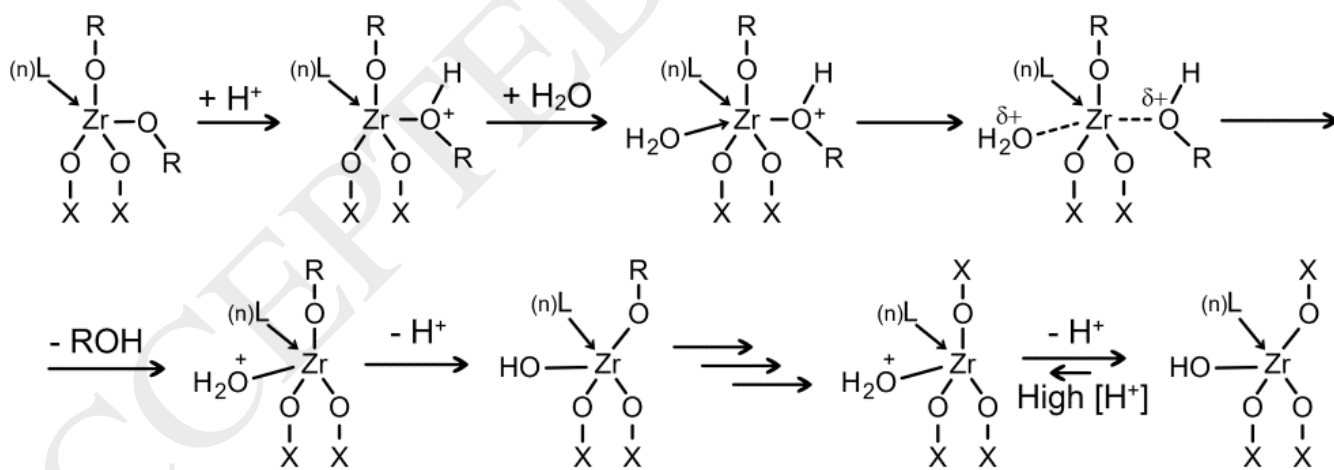

Prot-Zr

Hydr-Zr

where $\mathrm{R}=\mathrm{n}-\mathrm{C}_{3} \mathrm{H}_{7}, \mathrm{X}=\mathrm{H}$ or $\mathrm{Zr}, \mathrm{L}=\mathrm{n}-\mathrm{C}_{3} \mathrm{H}_{7} \mathrm{OH}$ or $\mathrm{H}_{2} \mathrm{O}, \mathrm{n}=1-4$

Scheme 2. a) Proposed mechanism for the formation of $\mathrm{ZrO}_{2}$ nanoparticles and colloidal particles (sols) under different acidity conditions. b) The representation of the assembly of primary and secondary globules to a self-supported wet gel structure. 
a)

@Moderate $\left[\mathrm{H}^{+}\right]$

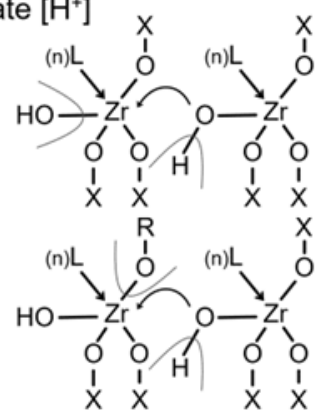<smiles>O=CC(C=O)[Mg][Mg]</smiles><smiles>[X]O[R]([X])([H])O[Ge]([Y])(O[X])O[V]</smiles>

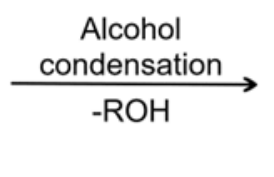<smiles>[X]O[Z]([Y])(O[V])O[Z]([AlH])(O[X])OC</smiles>

@Medium $\left[\mathrm{H}^{+}\right]$

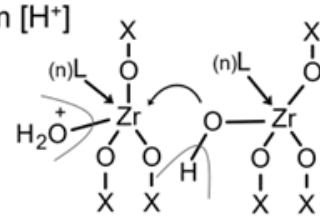<smiles></smiles>

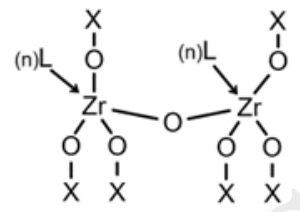

@High $\left[\mathrm{H}^{+}\right]$

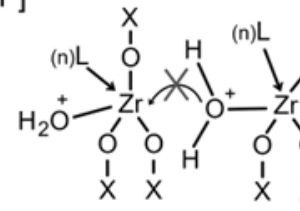

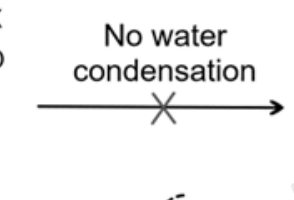

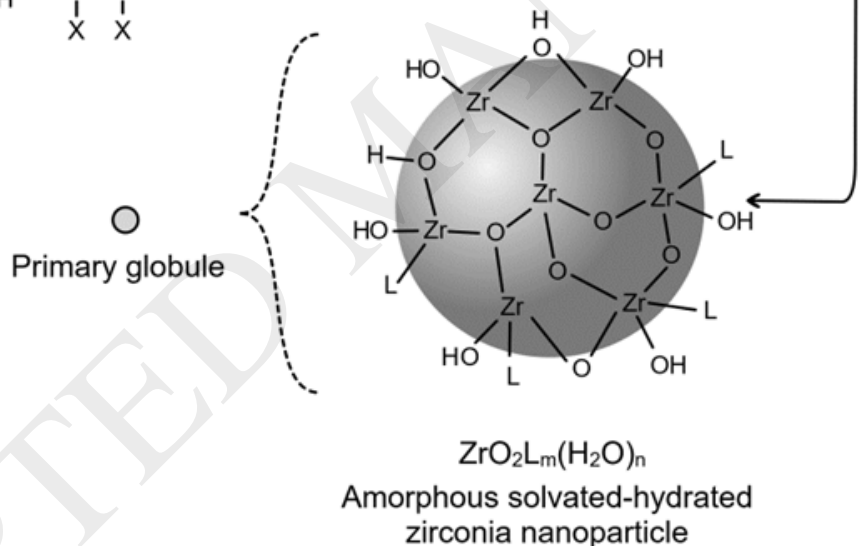

b) zirconia nanoparticle

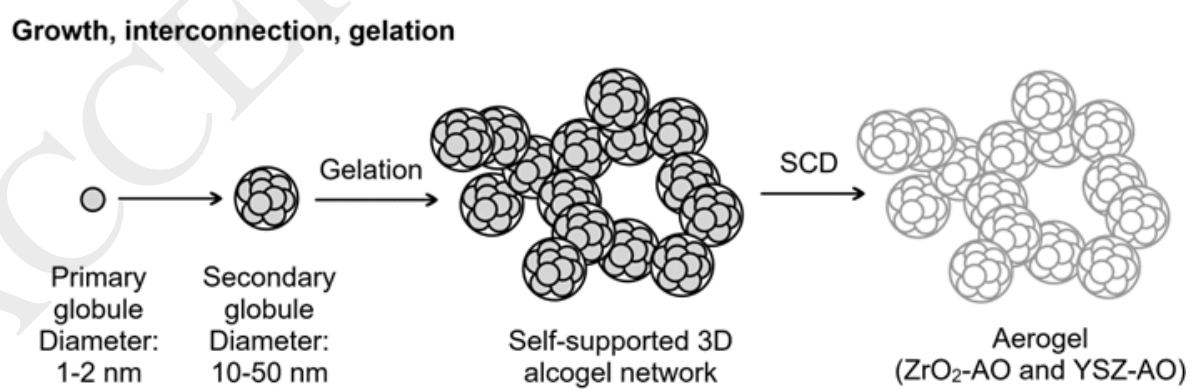

3.2. Thermal analysis of amorphous $\mathrm{ZrO}_{2}$ and $\mathrm{YSZ}$ aerogels 
The thermal analysis of the as-prepared amorphous $\mathrm{ZrO}_{2}-\mathrm{AO}$ and $\mathrm{YSZ}-\mathrm{AO}$ aerogels were performed in order to identify the presence of any energetic processes at high temperatures. The simultaneous TG and DSC results are shown in Figure 1. These plots also show the MS signals for $m / z: \mathrm{H}_{2} \mathrm{O}: 18, \mathrm{CO}: 28, \mathrm{CO}_{2}: 44, \mathrm{NO}_{\mathrm{x}}: 14,30$ and 46.

The first mass loss of the $\mathrm{ZrO}_{2}$ aerogel is at $121{ }^{\circ} \mathrm{C}(-7.84$ wt. \%) and the second one is in the range of $250-400{ }^{\circ} \mathrm{C}(-4.87$ wt. \%). According to the MS data, the products that are released from the aerogel are $\mathrm{H}_{2} \mathrm{O}$ and $\mathrm{CO}_{2}$ in both the first and the second mass loss steps. $\mathrm{H}_{2} \mathrm{O}$ is dominantly released at $121^{\circ} \mathrm{C}$ and the release of $\mathrm{CO}_{2}$ is characteristic at 250 - $400{ }^{\circ} \mathrm{C}$. At this elevated temperature, the combustion of the leftover synthesis compounds such as $n$-propanol and $\mathrm{HNO}_{3}$ also takes place and $\mathrm{CO}$ and $\mathrm{NO}_{\mathrm{x}}$ are produced. The DSC curve shows several thermal effects. The first broad exothermic peak at $70-$ $400{ }^{\circ} \mathrm{C}$ is consistent with the first and second mass loss steps, therefore, it is attributed to desorption and combustion processes. A sharp exothermic peak is present at $419{ }^{\circ} \mathrm{C}$ and is attributed to a phase transformation from amorphous to tetragonal phase $\left(t-\mathrm{ZrO}_{2}\right)$. There is no mass loss or MS signal at this temperature. Finally, a broad exothermic signal was detected that lies between 800 and $1100{ }^{\circ} \mathrm{C}$ with a maximum at ca. $842{ }^{\circ} \mathrm{C}$. This signal is related to the gradual phase transition from $t-\mathrm{ZrO}_{2}$ to monoclinic zirconia $\left(m-\mathrm{ZrO}_{2}\right)$. Both of the above discussed phase transitions were recognized by in-situ powder X-ray analysis as well, as described later in Section 3.6. As an additional thermal analysis step, the controlled cooling of the $\mathrm{ZrO}_{2}$ sample was performed for identifying further thermal processes upon quenching to room temperature. The corresponding TG and DSC plots are shown in Figure 1c. A single exothermic peak is detected at $818{ }^{\circ} \mathrm{C}$ which is related to the phase transition from $t-\mathrm{ZrO}_{2}$ to $m-\mathrm{ZrO}_{2}$ (see Section 3.6).

The TG and DSC curves together with selected MS signals for the as-prepared amorphous YSZ-AO aerogel are shown in Figure 1d-f. The TG curve shows two distinct 
mass loss steps at $121{ }^{\circ} \mathrm{C}(-7.59 \mathrm{wt} \%)$ and from 205 to $450{ }^{\circ} \mathrm{C}(-16.97 \mathrm{wt} \%)$. Similarly, to the $\mathrm{ZrO}_{2}-\mathrm{AO}$ sample, every mass loss step corresponds to an increase in the MS signal at $m / z$ of $18,28,44,30,14$ and 46 . The first mass loss step is the desorption of water at $121{ }^{\circ} \mathrm{C}$. In the second mass loss step, residual water is removed along with combustion products such as $\mathrm{CO}_{2}, \mathrm{CO}$, and $\mathrm{NO}_{\mathrm{x}}$. The DSC curve of the amorphous YSZ aerogel sample is similar to that of the $\mathrm{ZrO}_{2}$ sample. The first exothermic DSC peak from 70 to $400{ }^{\circ} \mathrm{C}$ is attributed to the release of heat due to combustion. The amorphous-to-tetragonal phase transition is detected at $455^{\circ} \mathrm{C}$. Interestingly, no thermal process occurs during the cooling of the YSZ sample (Figure 1f), indicating the absence of phase transition from $t$ $\mathrm{ZrO}_{2}$ to $m-\mathrm{ZrO}_{2}$.

The measured amorphous-to-tetragonal crystallization temperatures of $\mathrm{ZrO}_{2}$ and YSZ aerogels are $419{ }^{\circ} \mathrm{C}$ and $455^{\circ} \mathrm{C}$, respectively. The elevation of the crystallization temperature can be attributed to the presence of foreign species, such as ethoxy and nitrate groups in the YSZ aerogel. [10] This theory is supported by the significantly higher mass loss of the YSZ aerogel (-16.97 wt\%) compared that of the $\mathrm{ZrO}_{2}$ aerogel (-4.87 wt\%) below $400{ }^{\circ} \mathrm{C}$. The amount of combustion products is also much higher in the case of the YSZ sample. 

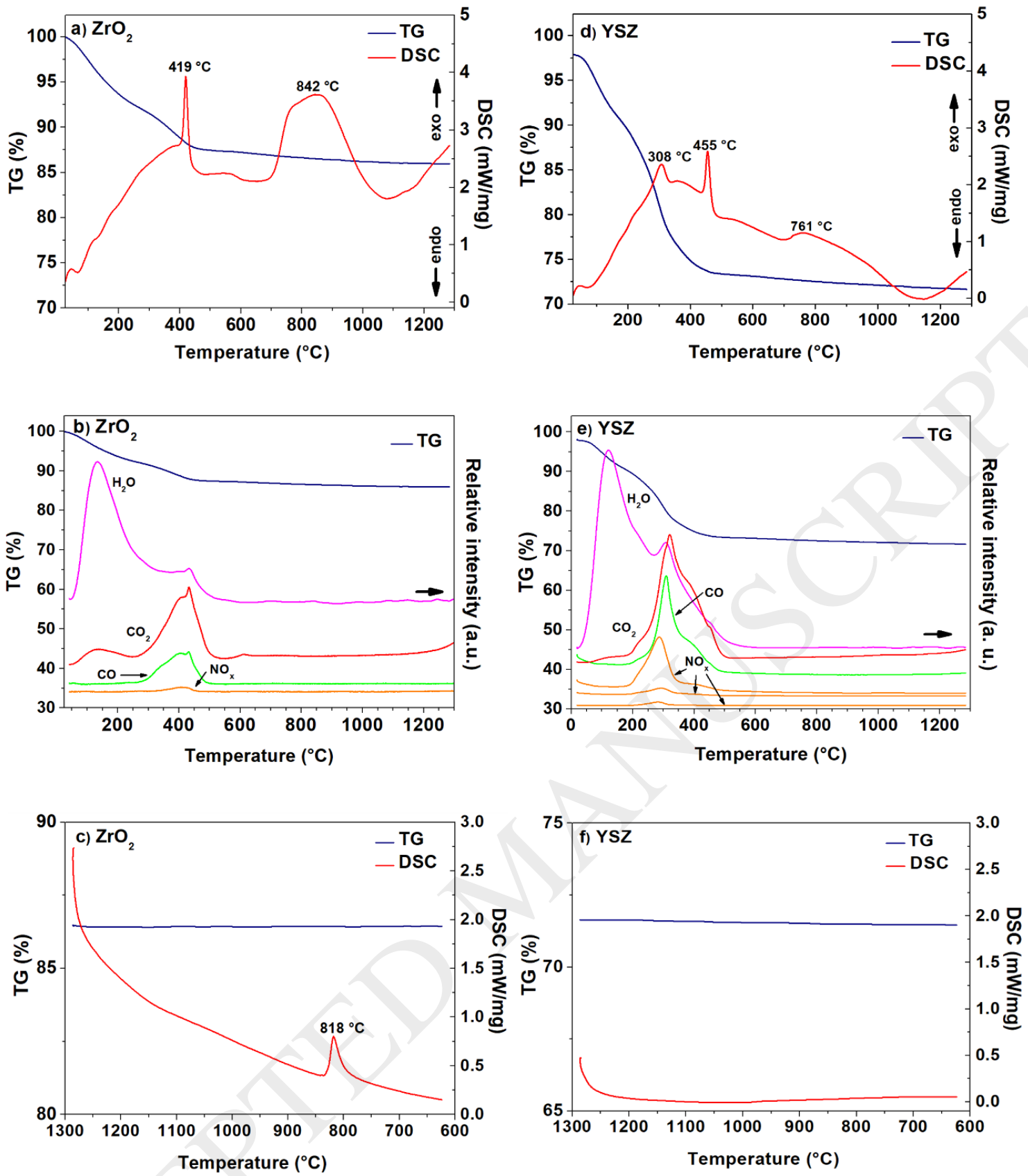

Figure 1. Results of the thermal analysis of the as-prepared amorphous $\mathrm{ZrO}_{2}-\mathrm{AO}$ and $\mathrm{YSZ}-\mathrm{AO}$ aerogels. Comparison of the simultaneous TG/DSC signals and MS signals at m/z: $\mathrm{H}_{2} \mathrm{O}: 18, \mathrm{CO}$ : 28, $\mathrm{CO}_{2}: 44$, and $\mathrm{NO}_{\mathrm{x}}: 14 ; 30 ; 46$, Graph a) and b): heating of the $\mathrm{ZrO}_{2}$ sample. Graph c): cooling of the same sample. Graph d) and e): heating of the YSZ sample. Graph f): cooling of the same sample. 


\subsection{Effect of calcination on the porosity of aerogels}

In order to determine the effect of calcination temperature on the porosity of $\mathrm{ZrO}_{2}$ and YSZ aerogels, $\mathrm{N}_{2}$ adsorption-desorption isotherms were measured before and after calcination at $500{ }^{\circ} \mathrm{C}$. The recorded $\mathrm{N}_{2}$ adsorption-desorption curves are type IV isotherms with H1-type hysteresis loops (Figure 2). [31] This confirms the presence of mesopores in all aerogel samples. The structural properties of the studied aerogels are summarized in Table 1.
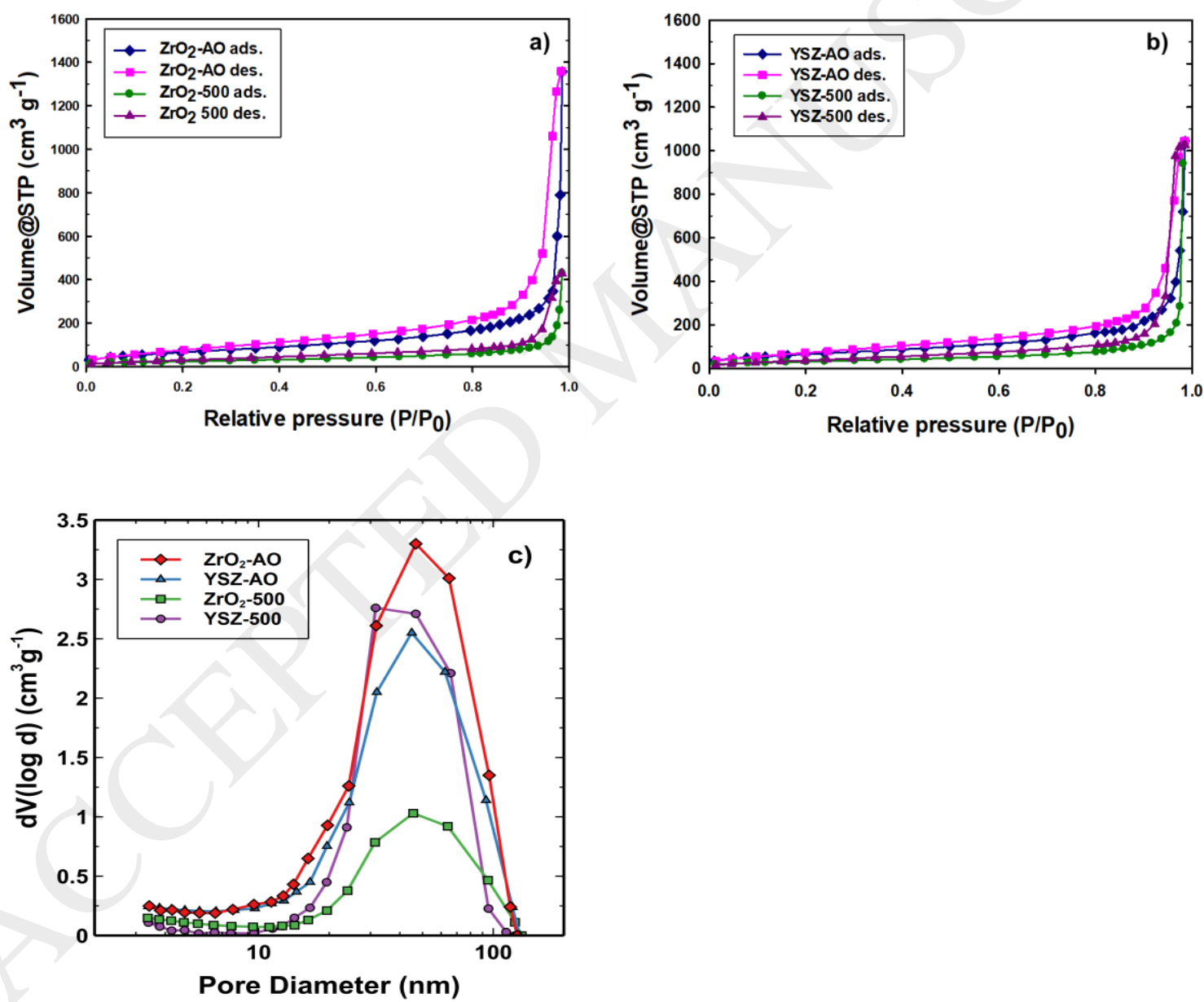

Figure 2. Nitrogen gas adsorption (ads) - desorption (des) isotherms of $\mathrm{ZrO}_{2}$ (a) and YSZ (b) aerogels as well as pore size distribution curves (c) before calcination $\left(\mathrm{ZrO}_{2}-\mathrm{AO}, \mathrm{YSZ}-\mathrm{AO}\right)$ and after calcination at $500{ }^{\circ} \mathrm{C}\left(\mathrm{ZrO}_{2}-500\right.$, YSZ-500). 
Table 1. Textural properties of the $\mathrm{ZrO}_{2}$ and $\mathrm{YSZ}$ aerogels before and after calcination. Standard deviations are displayed for primary data.

\begin{tabular}{|c|c|c|c|c|c|c|c|}
\hline Sample & $\begin{array}{l}S_{\text {BET }} \\
{\left[\mathrm{m}^{2} \mathbf{g}^{-1}\right]^{a)}}\end{array}$ & $\begin{array}{l}V \mathbf{p} \\
{\left[\mathrm{cm}^{3} \mathbf{g}^{-1}\right]^{\mathbf{b})}}\end{array}$ & $\begin{array}{l}V_{\text {mesopore }} \\
{\left[\mathrm{cm}^{3} \mathbf{g}^{-1}\right]^{\mathrm{c})}}\end{array}$ & $\begin{array}{l}V_{\text {macropore }} \\
{\left[\mathrm{cm}^{3} \mathrm{~g}^{-1}\right]^{\mathrm{d})}}\end{array}$ & $\begin{array}{l}D \mathbf{p} \\
(\mathbf{n m})^{\mathrm{e})}\end{array}$ & $\begin{array}{l}D_{\text {p-avg }} \\
(\mathbf{n m})^{\mathrm{f}}\end{array}$ & $C$-const. ${ }^{\mathrm{g})}$ \\
\hline $\mathrm{ZrO}_{2}-\mathrm{AO}$ & $255 \pm 21$ & $2.1 \pm 0.2$ & 1.4 & 0.71 & 47 & 33 & 39 \\
\hline $\mathrm{ZrO}_{2}-500$ & $87 \pm 13$ & $0.7 \pm 0.1$ & 0.46 & 0.19 & 46 & 31 & 86 \\
\hline YSZ-AO & $243 \pm 14$ & $1.6 \pm 0.1$ & 1.1 & 0.54 & 45 & 27 & 57 \\
\hline YSZ-500 & $114 \pm 19$ & $1.6 \pm 0.3$ & 1.3 & 0.35 & 37 & 56 & 83 \\
\hline
\end{tabular}

a) BET specific surface area; ${ }^{\text {b) }}$ Total pore volume; ${ }^{c)}$ Pore volume of mesopores; ${ }^{\text {d) }}$ Pore volume of macropores; ${ }^{\text {e) }}$ Characteristic pore diameter: estimated at the maximum of the distribution curve; ${ }^{\text {f) }}$ Average pore size: estimated by BJH method; ${ }^{g}$ Constant value as an indicator of the polarity of the sample surface. [28, 29]

The $\mathrm{ZrO}_{2}$-AO aerogel has an $S_{\mathrm{BET}}$ specific surface area of $255 \mathrm{~m}^{2} \mathrm{~g}^{-1}$ and a pore volume $\left(V_{p}\right)$ of $2.1 \mathrm{~cm}^{3} \mathrm{~g}^{-1}$. As expected, due to the shrinkage of the aerogel upon calcination at $500{ }^{\circ} \mathrm{C}$, these values decrease to $87 \mathrm{~m}^{2} \mathrm{~g}^{-1}$ and $0.7 \mathrm{~cm}^{3} \mathrm{~g}^{-1}$ representing a reduction of $66 \%$ and $31 \%$ for $S_{B E T}$ and $V_{p}$, respectively. On the other hand, the YSZ-AO aerogel has an $S_{B E T}$ value of $243 \mathrm{~m}^{2} \mathrm{~g}^{-1}$ and a $V_{p}$ of $1.6 \mathrm{~cm}^{3} \mathrm{~g}^{-1}$. Heat treatment at $500{ }^{\circ} \mathrm{C}$ for $2 \mathrm{~h}$ resulted in a drop of $S_{B E T}$ to $113 \mathrm{~m}^{2} \mathrm{~g}^{-1}(54 \%)$ but $V_{p}$ did not change $\left(1.6 \mathrm{~cm}^{3} \mathrm{~g}^{-1}\right)$. The measured specific surface areas are in good agreement with values published in the literature for zirconia aerogels prepared by the sol-gel method and supercritical drying. $[11,32-34]$ Characteristic pore sizes (the peak maximum of the distribution curve) are nearly identical for the as-obtained samples, and only moderately decrease upon heating at $500{ }^{\circ} \mathrm{C}$. Macropore volume is calculated as the cumulative pore volume of pores $d>$ $50 \mathrm{~nm}$. The micropore contribution to the entire surface area was calculated by using the 
t-plot method, based on the de Boer model of statistical thickness. [35] There are no pores below $d=2 \mathrm{~nm}$ in the aerogels.

The value of the $C$-constant is significantly higher for heat-treated samples, while the shape of the hysteresis loop remains unchanged. This indicates that the affinity of the probe gas $\left(\mathrm{N}_{2}\right)$ towards the aerogel surface is significantly different in $\mathrm{AO}$ and heat treated samples. [36] It is rational to assume that a portion of the surface is covered with residual $n$-propanol and unhydrolyzed propoxy groups in both the $\mathrm{ZrO}_{2}-\mathrm{AO}$ and YSZ-AO aerogels. This is in agreement with the detection of combustion products at ca. $400{ }^{\circ} \mathrm{C}$ during the thermal analysis of as-prepared $\mathrm{ZrO}_{2}-\mathrm{AO}$ and YSZ-AO samples (see Section 3.2 and Figure 1). The heat treatment of the aerogels at $500{ }^{\circ} \mathrm{C}$ results in the desorption of residual solvents. Calcination also initiates additional alcohol condensation of the neighboring $\mathrm{Zr}-\mathrm{OH}$ and $\mathrm{Zr}-\mathrm{OPr}$ groups yielding new $\mathrm{Zr}-\mathrm{O}-\mathrm{Zr}$ links. The removal of residual nonpolar $n$-propanol and propoxy groups can increase the polarity of the aerogel surface, which can explain the higher values of the $C$-constant for calcined samples.

The change of the total pore volume on heating indicates the degree of shrinkage, and thus can be a good benchmark of the dimensional stability of the aerogels. As seen in Table $1, \mathrm{ZrO}_{2}-\mathrm{AO}$ suffers a very significant shrinkage on heating at $500{ }^{\circ} \mathrm{C}$, indicated by the dramatic drop in pore volume from $2.1 \mathrm{~cm}^{3} \mathrm{~g}^{-1}$ to $0.7 \mathrm{~cm}^{3} \mathrm{~g}^{-1}$. A possible explanation is that a particle coarsening process takes place (see Section 3.4). On the other hand, YSZAO proved to be thermally and dimensionally more stable, because the pore volume was unchanged on heating. 


\subsection{Effect of calcination on surface morphology}

The surface morphology and the effect of calcination temperature on the aerogel microstructure were studied by scanning electron microscopy (SEM). Figure 3 shows the fine structure of the $\mathrm{ZrO}_{2}$ and YSZ aerogels before and after calcination at different temperatures. The as-obtained $\mathrm{ZrO}_{2}-\mathrm{AO}$ and $\mathrm{YSZ}-\mathrm{AO}$ aerogels have similar microstructures consisting of an amorphous and interconnected nanoparticles network with no visible differences among them. After calcination at $500{ }^{\circ} \mathrm{C}$, the morphology of both samples show a moderate restructuration. Particle sizes are a bit smaller and a small number of new macropore openings can be observed. Moreover, YSZ-500 shows viscous flow-related initial islet formation. The fine structure of YSZ-AO (Figure 3d) is shifted to a coarser pattern after calcination at $500{ }^{\circ} \mathrm{C}$ (Figure 3e) containing larger islets of globules. The change becomes characteristic and obvious at $1200^{\circ} \mathrm{C}$ (Figure 3f). At 1200 ${ }^{\circ} \mathrm{C}$, the particles grow considerably and start to consolidate to form compact agglomerates, that is indicative of an extensive sintering process. The $\mathrm{ZrO}_{2}$ aerogel is highly densified and the loss of almost all the porosity can be observed. Similar phenomena take place in the YSZ aerogel. Neither mesopores nor macropores are visible in the samples calcined at high temperature. An overall conclusion is that the SEM pictures are in good accordance with the porosimetry results (Figure 2, Table 1). 

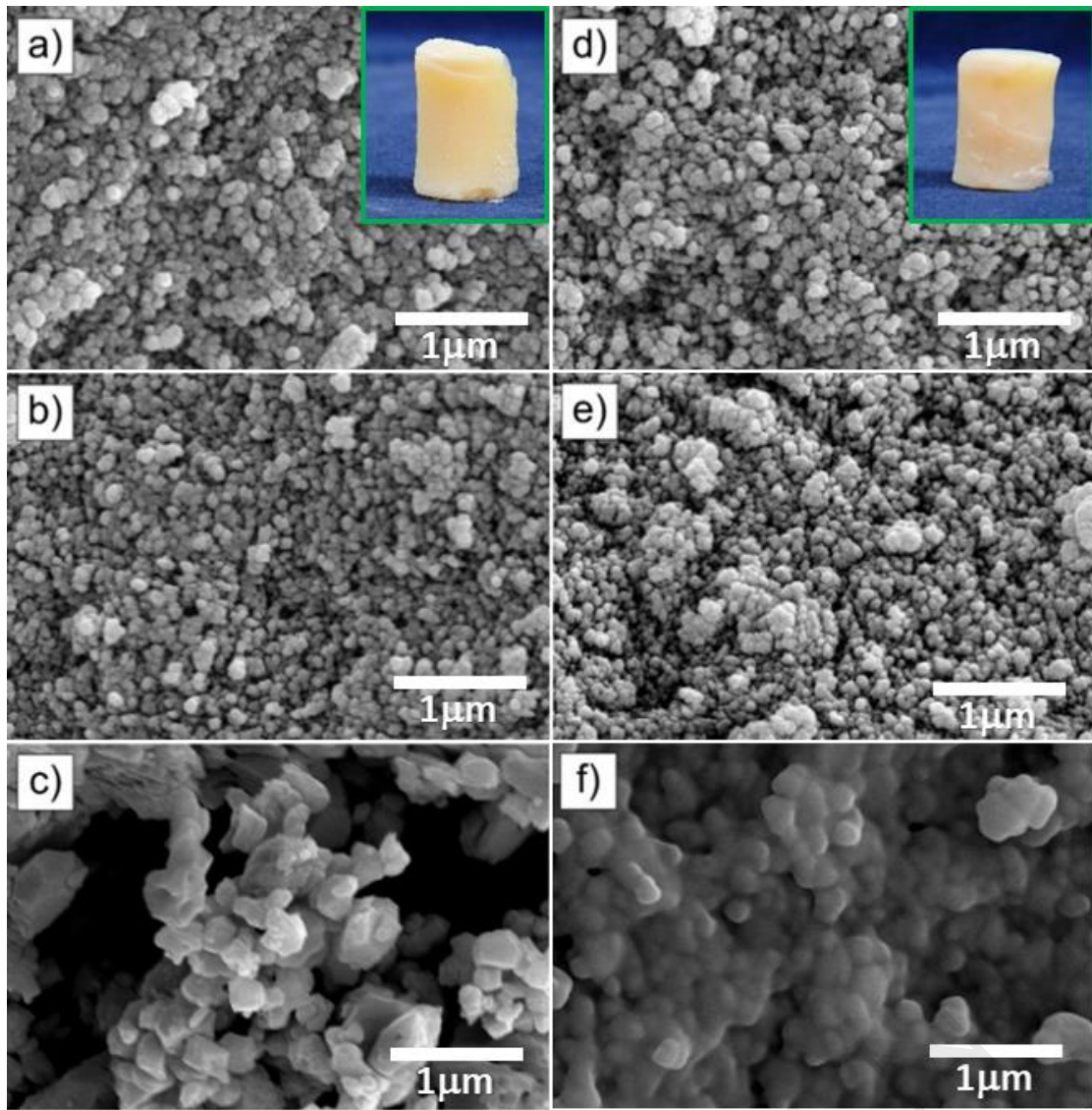

Figure 3. SEM images of the $\mathrm{ZrO}_{2}$ and $\mathrm{YSZ}$ aerogels before and after the heat treatment: a) $\mathrm{ZrO}_{2}$ $\mathrm{AO}$, b) $\mathrm{ZrO}_{2}-500$, c) $\mathrm{ZrO}_{2}-1200$, d) YSZ-AO, e) YSZ-500 and f) YSZ-1200. Insets: photographs of the $\mathrm{ZrO}_{2}-\mathrm{AO}$ and $\mathrm{YSZ}-\mathrm{AO}$ monoliths, respectively.

\subsection{Effect of calcination on the crystalline structure}

Ex-situ X-ray diffraction was used for the crystal structure determination of the asobtained aerogel samples (Figure 4). All samples were measured at room temperature after heat treatment. The pattern of the $\mathrm{ZrO}_{2}-\mathrm{AO}$ aerogel confirms that the characteristic amorphous phase is present in the as-prepared sample after supercritical drying. Upon calcination at $500{ }^{\circ} \mathrm{C}$ for $2 \mathrm{~h}$, the main diffraction peaks of monoclinic $\left(m-\mathrm{ZrO}_{2}\right.$, ICSD code: 18190$)$ and tetragonal $\left(t-\mathrm{ZrO}_{2}\right.$, ICSD code: 72950$)$ zirconia appear with oriented planes of (111), (111) and (011), (112) for monoclinic and tetragonal, respectively. In contrast with this, the calcination of the YSZ-AO sample at $500{ }^{\circ} \mathrm{C}$ yields a pure $t-\mathrm{ZrO}_{2}$ 
phase. The calcination of the $\mathrm{ZrO}_{2}$ aerogel at $1200{ }^{\circ} \mathrm{C}$ and cooling to room temperature induces the transition from $t-\mathrm{ZrO}_{2}$ to $m-\mathrm{ZrO}_{2}$ as only the $m-\mathrm{ZrO}_{2}$ is present in the $\mathrm{ZrO}_{2}$ 1200 sample. Such a phase transformation is in good agreement with the exothermic peak detected during the cooling DSC curve at $818^{\circ} \mathrm{C}$ (see Section 3.2 and Figure 1c). On the other hand, the YSZ-1200 aerogel conserves the stable $t-\mathrm{ZrO}_{2}$ phase after cooling to room temperature.
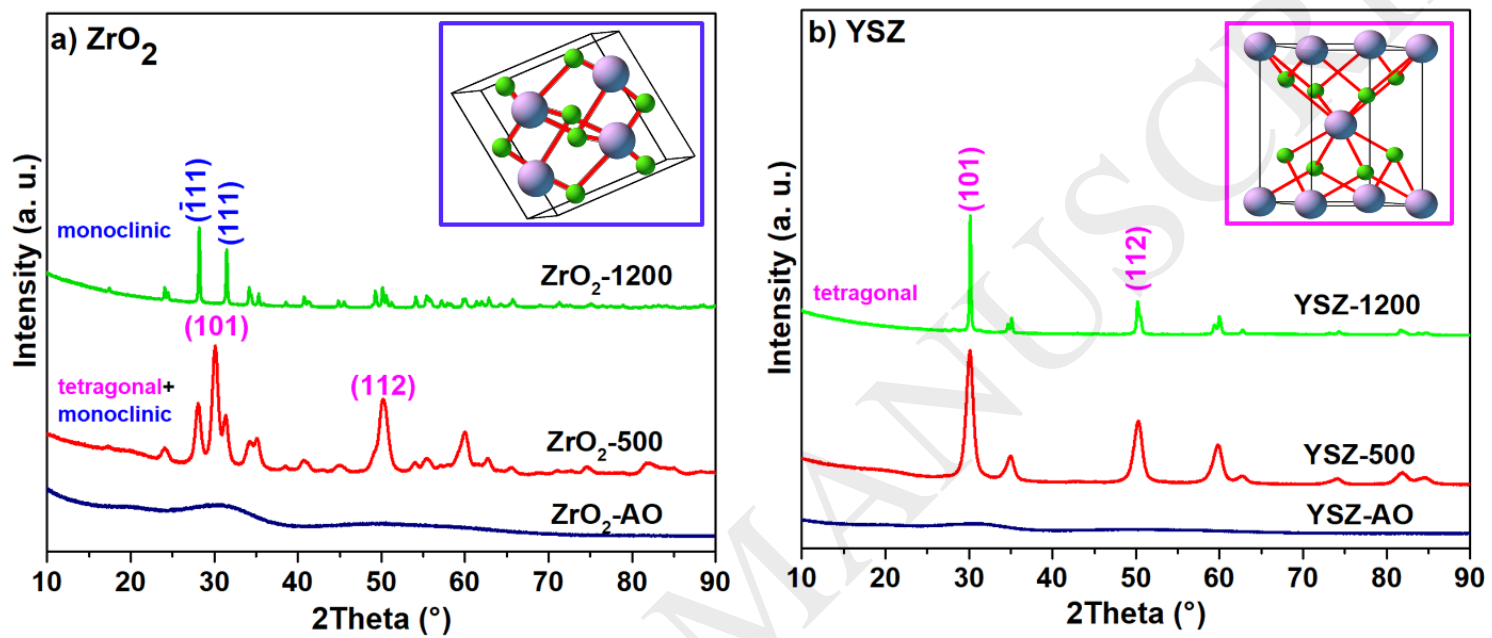

Figure 4. X-Ray diffraction patterns of a) $\mathrm{ZrO}_{2}$ and b) $\mathrm{YSZ}$ aerogels before and after calcination at $500{ }^{\circ} \mathrm{C}$ and $1200{ }^{\circ} \mathrm{C}$ for $2 \mathrm{~h}$. The diffraction patterns were taken after cooling to room temperature. Inset: monoclinic and tetragonal crystalline structures of $\mathrm{ZrO}_{2}$.

\subsection{Crystalline phase transitions during heat treatment}

The phase diagram established in 1975 by Scott shows that for pure $\mathrm{ZrO}_{2}$, the $t-\mathrm{ZrO}_{2}$ phase exists in the temperature range of $1170-2370{ }^{\circ} \mathrm{C}$. [37] However, our findings with ex-situ XRD (Figure 4) seem to have an inconsistency with this phase diagram. The asobtained (amorphous) $\mathrm{ZrO}_{2}-\mathrm{AO}$ aerogel partially crystallizes to $t-\mathrm{ZrO}_{2}$ upon a heat treatment at $500{ }^{\circ} \mathrm{C}$, which is far from the transformation temperature of $t-\mathrm{ZrO}_{2}$ described in the phase diagram. Thus, we designed a step-by-step experiment to study the effect of 
temperature on the crystallographic evolution of both the $\mathrm{ZrO}_{2}$ and the $\mathrm{YSZ}$ aerogels. Insitu XRD measurements were performed at every $100{ }^{\circ} \mathrm{C}$ during the heat treatment of the amorphous $\mathrm{ZrO}_{2}-\mathrm{AO}$ and $\mathrm{YSZ}-\mathrm{AO}$ samples up to $1200{ }^{\circ} \mathrm{C}$. These temperature dependent XRD patterns are shown in Figure 5. The analyses were performed from $2 \theta=22$ to $37^{\circ}$, because the main diffraction peaks of $m-\mathrm{ZrO}_{2}$ and $t-\mathrm{ZrO}_{2}$ can be clearly detected in this range.

The $\mathrm{ZrO}_{2}$-AO sample remained unchanged up to $400{ }^{\circ} \mathrm{C}$ where only amorphous zirconia was detected. At $500{ }^{\circ} \mathrm{C}$, partial crystallization occurs and the XRD pattern displays a diffraction peak of $t-\mathrm{ZrO}_{2}$ with (011) orientation showing the formation of a dominantly tetragonal phase. New diffraction peaks appear above $700{ }^{\circ} \mathrm{C}$ corresponding to $m-\mathrm{ZrO}_{2}$ with oriented planes (111) and (111) indicating that the tetragonal phase is transforming into a monoclinic phase. As the temperature increases to $1000{ }^{\circ} \mathrm{C}$, the tetragonal peaks are gradually reduced, while the monoclinic peaks become more expressed. Parallel to this, the diffraction peaks become sharper with increasing calcination temperature, indicating the increase of crystallite size. At $1100{ }^{\circ} \mathrm{C}$, most of the $m-\mathrm{ZrO}_{2}$ phase is transformed to $t-\mathrm{ZrO}_{2}$ marking transformation temperature from monoclinic-to-tetragonal. During the cool-down process, $t$ - $\mathrm{ZrO}_{2}$ transforms to $m-\mathrm{ZrO}_{2}$, as $m-\mathrm{ZrO}_{2}$ is the stable form of $\mathrm{ZrO}_{2}$ at room temperature. In order to summarize the observations, it can be stated that pure zirconia aerogel is composed of either a single phase or a mixture of tetragonal and monoclinic phases between 25 and $1200{ }^{\circ} \mathrm{C}$.

The YSZ-AO aerogel remains amorphous up to $400{ }^{\circ} \mathrm{C}$ (Figure 5). At $500{ }^{\circ} \mathrm{C}$, a $t-\mathrm{ZrO}_{2}$ diffraction peak appears which corresponds to the crystalline plane (011). The $\mathrm{ZrO}_{2}$ sample behaves similarly. However, in contrast to the $\mathrm{ZrO}_{2}$ aerogel, no new diffraction peaks appear for the YSZ aerogel upon heating up to $1200{ }^{\circ} \mathrm{C}$. Furthermore, the tetragonal phase is conserved even when the sample is cooled to room temperature. This is an 
obvious demonstration of the well-known stabilizing effect of yttrium ions $\left(\mathrm{Y}^{3+}\right)$ in the YSZ structure, promoting the formation of high purity tetragonal zirconia.
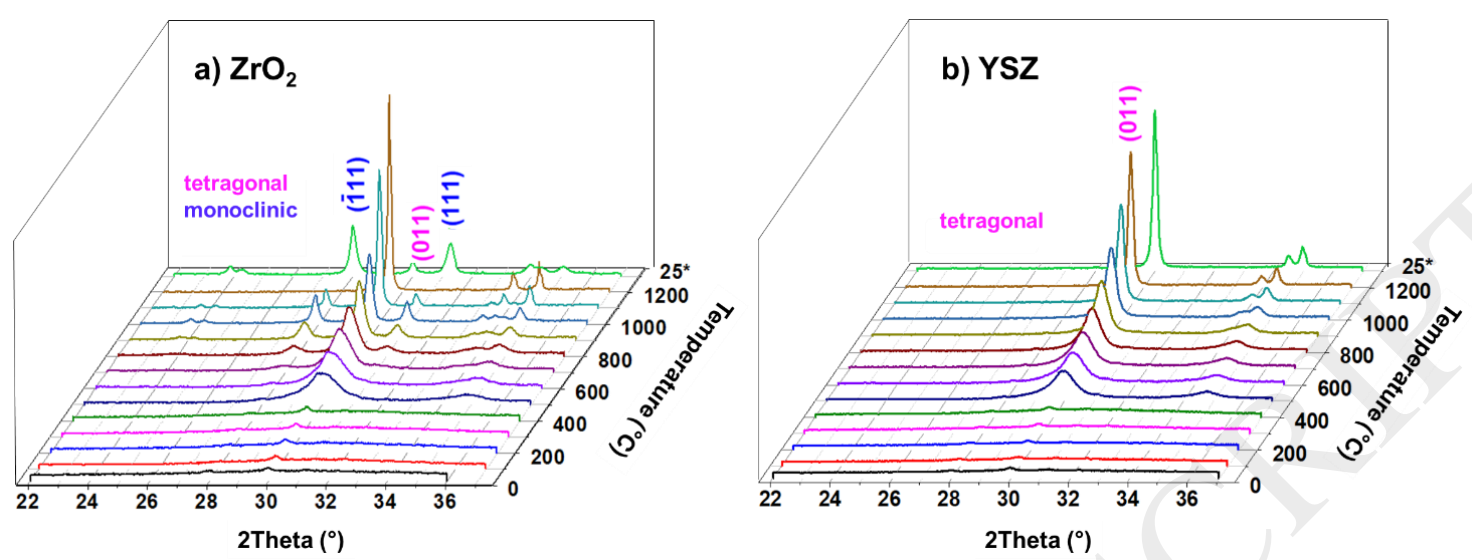

Figure 5. Temperature dependent XRD patterns of a) $\mathrm{ZrO}_{2}$ and b) YSZ aerogels. In-situ XRD measurements from 25 to $1200{ }^{\circ} \mathrm{C}$ were performed during the calcination of the amorphous aerogels in order to determine their crystallographic evolution. The last pattern $\left(25^{*}\right)$ was recorded upon quenching.

On the basis of the results of the in-situ XRD, the phase evolution of the $\mathrm{ZrO}_{2}$ aerogel takes place during thermal treatment as follows: $i$ ) the initial dominantly amorphous phase transforms to a tetragonal phase at $419{ }^{\circ} \mathrm{C}$; ii) in the temperature range of $500-1000{ }^{\circ} \mathrm{C}$, a tetragonal-to-monoclinic phase transformation occurs, leading to the coexistence of a mixture of tetragonal and monoclinic phases; iii) the monoclinic phase is transformed to a tetragonal-dominant phase at $1100{ }^{\circ} \mathrm{C}$ with a complete transformation at $1200{ }^{\circ} \mathrm{C}$; and $i v)$ the purely tetragonal phase is transformed into a purely monoclinic phase on cooling to room temperature.

It is worth to note that the diffraction peaks are sharper at higher temperatures (Figure 5). This indicates that the size of the nanometer-wide crystallites increases with increasing calcination temperature. In order to quantify the relation between phase transformation 
and crystallite growth, crystallite size was calculated using Scherrer's equation (Equation 1) and the crystalline phase composition of the aerogel was calculated through the Rietveld refinement. The ICSD reference patterns of $m-\mathrm{ZrO}_{2}$ (ICSD code: 18190) and $t$ $\mathrm{ZrO}_{2}$ (ICSD code: 72950) were recalculated. For the $\mathrm{ZrO}_{2}$ aerogel, the gradual phase transformation and the crystallite size growth are shown as a function of temperature in Figure 6.

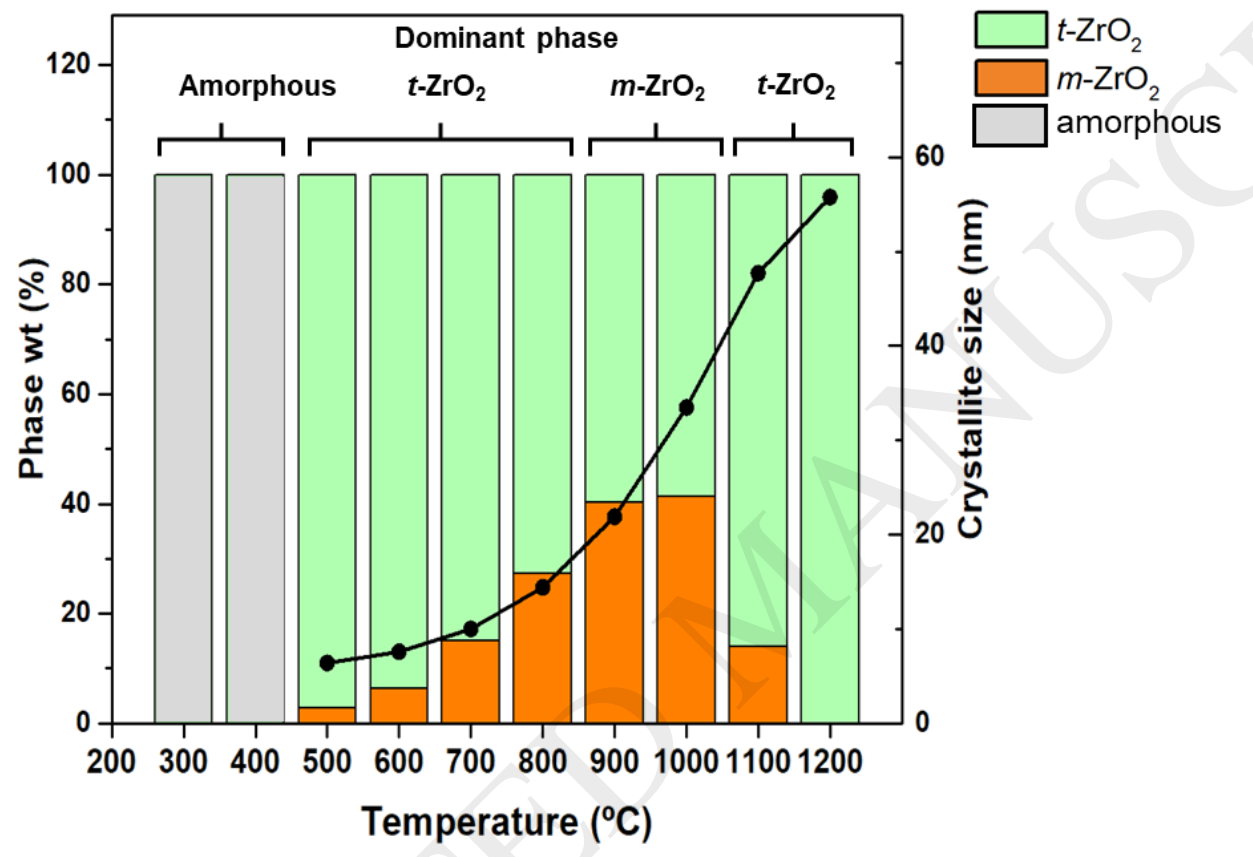

Figure 6. The crystalline phase transitions of $\mathrm{ZrO}_{2}$ aerogel during heat treatment. Correlation between the composition of the crystalline phase and crystallite size at different temperatures.

Sparsely distributed nanocrystals can exist in the amorphous matrix of the as-prepared $\mathrm{ZrO}_{2}-\mathrm{AO}$ aerogel. [38] Such crystallites can be either monoclinic or tetragonal and can behave as preferential sites for grain growth in the dominantly amorphous $\mathrm{ZrO}_{2}$. At 500 ${ }^{\circ} \mathrm{C}, \mathrm{ZrO}_{2}$ partially crystallizes to mainly $t-\mathrm{ZrO}_{2}$ composed of small crystallites of ca. $6 \mathrm{~nm}$ (Figure 6). These nanocrystals grow within the range of $20-31 \mathrm{~nm}$ at $1000{ }^{\circ} \mathrm{C}$ as the 
amount of $t-\mathrm{ZrO}_{2}$ decreases and $m-\mathrm{ZrO}_{2}$ forms. With increasing temperature, $t-\mathrm{ZrO}_{2}$ becomes dominant until a single-phase material is obtained at $1200{ }^{\circ} \mathrm{C}$ with a mean crystallite size of $45-52 \mathrm{~nm}$.

Thus, our findings suggest that the tetragonal phase can exist in a nanometer-size domain even at lower temperatures than reported in the phase diagram of $\mathrm{ZrO}_{2}$. Several studies have reported the existence of the tetragonal phase at room temperature and provided various explanations for such behavior. Garvie stated that the crystallite size and therefore, the free energy has an effect on the stabilization of the tetragonal crystalline phase. [39] In other words, $m-\mathrm{ZrO}_{2}$ has a lower bulk free energy but $t-\mathrm{ZrO}_{2}$ has a lower surface free energy. For crystallites below a certain critical size $(30 \mathrm{~nm})$, the surface free energy term dominates over the bulk free energy term and the stabilization of the tetragonal phase becomes favorable. Moreover, Bedilo suggested that tetragonal zirconia can exist at room temperature due the presence of organic compounds in the as-prepared aerogel matrix, as a consequence of the of sol-gel technique. [17] The burning of these organic residues during calcination leads to local overheating and the stabilization of $t$ $\mathrm{ZrO}_{2}$. Mitsuhashi et al. reported that such stabilization is due to strain effects in the nanoparticle regime. [40] Others proposed that the formation of $t-\mathrm{ZrO}_{2}$ is due to the short range structural similarities between the amorphous phase and the $t-\mathrm{ZrO}_{2}$ phase. [41-43] Garvie proposed that during calcination, initially a trace amount of $m-\mathrm{ZrO}_{2}$ forms, because a small portion of the crystallites are bigger than the critical phase transition size. At higher temperatures, the size of the crystallites increases and the entire sample transforms to $m-\mathrm{ZrO}_{2}$.

Our experimental results clearly show that the phase transformation of $\mathrm{ZrO}_{2}$ is complemented by crystallite size growth with increasing temperature. Furthermore, a close correlation can be identified between temperature and crystallite size in controlling 
the phase stability of zirconia (Figure S2). [44] First, the amorphous $\mathrm{ZrO}_{2}$ transforms into a $t-\mathrm{ZrO}_{2}$ phase (crystallite size: $6.0-13.6 \mathrm{~nm}$ ) in a thermodynamically controlled process that finishes at ca. $800{ }^{\circ} \mathrm{C}$. As the temperature increases to $900{ }^{\circ} \mathrm{C}$, the crystallite size approaches the critical size of $t-\mathrm{ZrO}_{2}(30 \mathrm{~nm})$ and the thermodynamic stability of the tetragonal and monoclinic phases become comparable. This results in a tetragonal-tomonoclinic phase transformation which becomes clearly visible at $1000{ }^{\circ} \mathrm{C}$ where the critical crystallite size is reached $(31.7 \mathrm{~nm})$. The temperature component becomes dominant again close to the monoclinic-to-tetragonal phase transformation temperature of $1170{ }^{\circ} \mathrm{C}$. Subsequent heating at $1200{ }^{\circ} \mathrm{C}$ leads to the complete transformation to a pure tetragonal phase.

\section{Conclusions}

The acid-catalyzed sol-gel method was successfully applied to synthesize monolithic $\mathrm{ZrO}_{2}$ and YSZ aerogels. A detailed molecular-level mechanism is proposed for the formation of the 3D wet gel network. The as-prepared monoliths were calcined at different temperatures between 300 and $1200{ }^{\circ} \mathrm{C}$. The temperature of calcination has a marked effect on the textural properties, and the crystallinity of the aerogels. In general, the specific surface area and the total pore volume decrease on calcination regardless of the composition of the aerogels.

The YSZ sample crystallizes into a single-phase tetragonal zirconia at $455^{\circ} \mathrm{C}$ and this phase is retained up to $1200{ }^{\circ} \mathrm{C}$. Importantly, the tetragonal phase is conserved in the YSZ aerogel after cooling to room temperature. Depending on the temperature, the pure $\mathrm{ZrO}_{2}$ aerogel can exist in either a single tetragonal phase (from $419^{\circ} \mathrm{C}$ to $800{ }^{\circ} \mathrm{C}$ and over 1100 ${ }^{\circ} \mathrm{C}$ ), or in a single monoclinic phase (between $900{ }^{\circ} \mathrm{C}$ and $1000^{\circ} \mathrm{C}$ ), as well as in a mixture of these two phases. The evolution of the crystallinity of the $\mathrm{ZrO}_{2}$ aerogel was studied as a function of calcination temperature by in-situ XRD measurements. We show that the 
phase transformation of $\mathrm{ZrO}_{2}$ is complemented by crystallite size growth. Furthermore, a close correlation between temperature and crystallite size can be identified, controlling the phase stability of zirconia. An important observation is, that the mixed tetragonal and monoclinic phases are conserved when a pure $\mathrm{ZrO}_{2}$ aerogel is calcined at $500{ }^{\circ} \mathrm{C}$, but calcination at $1200{ }^{\circ} \mathrm{C}$ yields pure monoclinic zirconia, because a tetragonal-tomonoclinic transformation takes place on cooling to room temperature. Based on observations it is now possible to tailor physical and phase properties of zirconia aerogels for high temperature applications.

\section{Acknowledgements}

This research has been financially supported by the Ministry of Education, Youth and Sports of the Czech Republic under the project CEITEC 2020 (LQ1601). This work was supported by the ESF under the project CZ.02.2.69/0.0/0.0/18_070/0009469. Also, the authors thank the Hungarian Science Foundation (OTKA: FK_17-124571 and K_17124983) for financial support. J. Kalmár was supported by the ÚNKP-17-4 NEW NATIONAL EXCELLENCE PROGRAM of the Ministry of Human Capacities, Hungary. The research was supported by the EU and co-financed by the European Regional Development Fund under the projects GINOP-2.3.2-15-2016-00008 and GINOP-2.3.2-15-2016-00041 projects. Part of the work was carried out with the support of CEITEC Nano Research Infrastructure (MEYS CR, 2016-2019). 


\section{References}

[1] S.S. Kistler, Coherent Expanded-Aerogels, J. Phys. Chem., 36 (1931) 52-64.

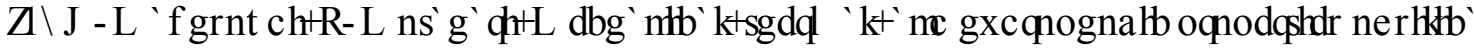
'dquf dk donwx bnl onrhsdr+J. Appl. Polym. Sci., 135 (2018) 45706.

[3] S. Iswar, W.J. Malfait, S. Balog, F. Winnefeld, M. Lattuada, M.M. Koebel, Effect of aging on silica aerogel properties, Micropor Mesopor Mat, 241 (2017) 293-302.

[4] L.W. Hrubesh, Aerogel applications, J Non-Cryst Solids, 225 (1998) 335-342.

[5] I. Smirnova, P. Gurikov, Aerogel production: Current status, research directions, and future opportunities, J. Supercrit. Fluid, 134 (2018) 228-233.

[6] C. Ziegler, S. Klosz, L. Borchardt, M. Oschatz, S. Kaskel, M. Friedrich, R. Kriegel, T. Keilhauer, M. Armbruster, A. Eychmuller, $\mathrm{ZnPd} / \mathrm{ZnO}$ Aerogels as Potential Catalytic Materials, Adv. Funct. Mater., 26 (2016) 1014-1020.

[7] J.F. Liu, N.W. Liu, K.Q. Ren, L. Shi, X. Meng, Sulfated Zirconia Synthesized in a One Step Solvent-Free Method for Removal of Olefins from Aromatics, Ind Eng Chem Res, 56 (2017) 7693-7699.

[8] C.C. Wei, K. Li, Yttria-stabilized zirconia (YSZ)-based hollow fiber solid oxide fuel cells, Ind Eng Chem Res, 47 (2008) 1506-1512.

[9] P. Khajavi, A.A. Babaluo, A. Tavakoli, A. Mirzaei, Stabilization of the Metastable Tetragonal Phase in Zirconia Nanopowders Synthesized via Polyacrylamide Gel Method, Ind Eng Chem Res, 53 (2014) 164-172.

[10] C. Stocker, A. Baiker, Zirconia aerogels: effect of acid-to-alkoxide ratio, alcoholic solvent and supercritical drying method on structural properties, J Non-Cryst Solids, 223 (1998) 165-178.

[11] N. Shimoda, K. Nakayama, K. Kiyota, S. Satokawa, Synthesis of tetragonal zirconia in mesoporous silica and its catalytic properties for methanol oxidative decomposition, RSC Adv., 7 (2017) 55819-55829.

[12] B. Tyagi, K. Sidhpuria, B. Shaik, R.V. Jasra, Synthesis of Nanocrystalline Zirconia Using Sol-Gel and Precipitation Techniques, Ind Eng Chem Res, 45 (2006) 8643-8650.

[13] J. Fenech, C. Viazzi, J.P. Bonino, F. Ansart, A. Barnabe, Morphology and structure of YSZ powders: Comparison between xerogel and aerogel, Ceram. Int., 35 (2009) 34273433.

[14] D.J. Suh, T.J. Park, Sol-Gel Strategies for Pore Size Control of High-Surface-Area Transition-Metal Oxide Aerogels, Chem. Mater., 8 (1996) 509-513.

[15] D.J. Suh, T.J. Park, H.Y. Han, J.C. Lim, Synthesis of high-surface-area zirconia aerogels with a well-developed mesoporous texture using $\mathrm{CO} 2$ supercritical drying, Chem. Mater., 14 (2002) 1452-1454.

[16] A. Benad, F. Jurries, B. Vetter, B. Klemmed, R. Hubner, C. Leyens, A. Eychmuller, Mechanical Properties of Metal Oxide Aerogels, Chem. Mater., 30 (2018) 145-152.

[17] A.F. Bedilo, K.J. Klabunde, Synthesis of high surface area zirconia aerogels using high temperature supercritical drying, Nanostruct. Mater., 8 (1997) 119-135.

[18] T. Gotsch, W. Wallisch, M. Stoger-Pollach, B. Klotzer, S. Penner, From zirconia to yttria: Sampling the YSZ phase diagram using sputter-deposited thin films, Aip Adv, 6 (2016) 025119.

[19] C.N. Chervin, B.J. Clapsaddle, H.W. Chiu, A.E. Gash, J.H. Satcher, S.M. Kauzlarich, Aerogel Synthesis of Yttria-Stabilized Zirconia by a Non-Alkoxide Sol-Gel Route, Chem. Mater., 17 (2005) 3345-3351.

[20] Z. Zhao, D. Chen, X. Jiao, Zirconia Aerogels with High Surface Area Derived from Sols Prepared by Electrolyzing Zirconium Oxychloride Solution: Comparison of 
Aerogels Prepared by Freeze-Drying and Supercritical CO2(1) Extraction, J. Phys. Chem. C, 111 (2007) 18738-18743.

[21] J.B. Miller, S.E. Rankin, E.I. Ko, Strategies in Controlling the Homogeneity of Zirconia Silica Aerogels - Effect of Preparation on Textural and Catalytic Properties, J. Catal., 148 (1994) 673-682.

[22] Z.G. Wu, Y.X. Zhao, D.S. Liu, The synthesis and characterization of mesoporous silica-zirconia aerogels, Micropor Mesopor Mat, 68 (2004) 127-132.

[23] G.Q. Zu, J. Shen, L.P. Zou, W.B. Zou, D.Y. Guan, Y. Wu, Y.W. Zhang, Highly thermally stable zirconia/silica composite aerogels prepared by supercritical deposition, Micropor Mesopor Mat, 238 (2017) 90-96.

[24] Q. Sun, Y.L. Zhang, J.F. Deng, S.Y. Chen, D. Wu, A novel preparation process for thermally stable ultrafine tetragonal zirconia aerogel, Appl. Catal. A, 152 (1997) L165L171.

[25] C. Brinker, Scherer G., Sol-Gel Science, London, 1990.

[26] I. Lázár, I. Fábián, A continuous extraction and pumpless supercritical $\mathrm{CO}_{2}$ drying system for laboratory-scale aerogel production, Gels, 2 (2016) 26.

[27] F.T. Muniz, M.A. Miranda, C. Morilla Dos Santos, J.M. Sasaki, The Scherrer equation and the dynamical theory of X-ray diffraction, Acta Crystallogr. A, 72 (2016) 385-390.

[28] K. Sing, The use of nitrogen adsorption for the characterisation of porous materials, Colloid. Surface. A, 187 (2001) 3-9.

[29] M. Thommes, K. Kaneko, A.V. Neimark, J.P. Olivier, F. Rodriguez-Reinoso, J. Rouquerol, K.S.W. Sing, Physisorption of gases, with special reference to the evaluation of surface area and pore size distribution (IUPAC Technical Report), Pure Appl. Chem., 87 (2015) 1051-1069.

[30] IUPAC, Stability Constants Database: Mini-SCDatabase Software, Stability Constants Database: Mini-SCDatabase Software: http://www.acadsoft.co.uk, (accessed: June-2018).

[31] S.K.S. Gregg S. J., Adsorption, surface area and porosity, New York, 1982.

[32] H. Gao, Z. Zhang, Z. Shi, J. Zhang, M. Zhi, Z. Hong, Synthesis of high-temperature resistant monolithic zirconia-based aerogel via facile water glass assisted sol-gel method, J. Sol-Gel Sci. Technol., 85 (2018) 567-573.

[33] Z. Shi, H. Gao, X. Wang, C. Li, W. Wang, Z. Hong, M. Zhi, One-step synthesis of monolithic micro-nano yttria stabilized $\mathrm{ZrO}_{2}-\mathrm{Al}_{2} \mathrm{O}_{3}$ composite aerogel, Micropor Mesopor Mat, 259 (2018) 26-32.

[34] Z.Y. Zhang, Q.Y. Gao, Y. Liu, C.M. Zhou, M.J. Zhi, Z.L. Hong, F. Zhang, B. Liu, A facile citric acid assisted sol-gel method for preparing monolithic yttria-stabilized zirconia aerogel, RSC Adv., 5 (2015) 84280-84283.

[35] C.J. Gommes, A.P. Roberts, Stochastic analysis of capillary condensation in disordered mesopores, Phys. Chem. Chem. Phys., 20 (2018) 13646-13659.

[36] D. Dollimore, P. Spooner, A. Turner, The bet method of analysis of gas adsorption data and its relevance to the calculation of surface areas, Surface Technology, 4 (1976) 121-160.

[37] H.G. Scott, Phase relationships in the zirconia-yttria system, J. Mater. Sci., 10 (1975) $1527-1535$.

[38] D.A. Ward, E.I. Ko, Synthesis and Structural Transformation of Zirconia Aerogels, Chem. Mater., 5 (1993) 956-969.

[39] R.C. Garvie, The Occurrence of Metastable Tetragonal Zirconia as a Crystallite Size Effect, J. Phys. Chem., 69 (1965) 1238-1243. 
[40] T. Mitsuhashi, M. Ichihara, U. Tatsuke, Characterization and stabilization of metastable tetragonal $\mathrm{ZrO}_{2}$, J. Am. Ceram. Soc., 57 (1974) 97-101.

[41] V.G. Keramidas, W.B. White, Raman Scattering Study of the Crystallization and Phase Transformations of $\mathrm{ZrO}_{2}$, J. Am. Chem. Soc., 57 (1974) 22-24.

[42] J. Li Vage, K. Doi, C. Mazieres, Nature and Thermal Evolution of Amorphous Hvdrated Zirconium Oxide, J. Am. Chem. Soc., 51 (1968) 349-353.

[43] E. Tani, M. Yoshimura, S. Somiya, Formation of Ultrafine Tetragonal $\mathrm{ZrO}_{2}$ Powder under Hydrothermal Conditions, J. Am. Ceram. Soc., 66 (1983) 11-14.

[44] X.X. Xu, X. Wang, Fine Tuning of the Sizes and Phases of ZrO2 Nanocrystals, Nano Res., 2 (2009) 891-902. 